\title{
Design of Storage Systems Using Multiple Storage Technologies in Renewable
} Systems

A. Lamont

January 17, 2001

U.S. Department of Energy

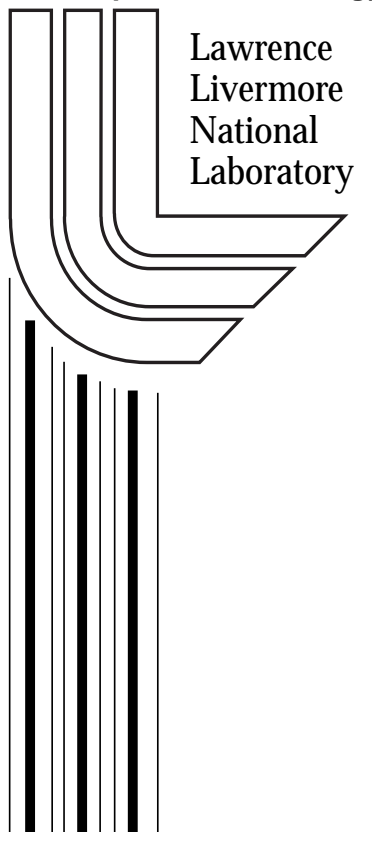




\section{DISCLAIMER}

This document was prepared as an account of work sponsored by an agency of the United States Government. Neither the United States Government nor the University of California nor any of their employees, makes any warranty, express or implied, or assumes any legal liability or responsibility for the accuracy, completeness, or usefulness of any information, apparatus, product, or process disclosed, or represents that its use would not infringe privately owned rights. Reference herein to any specific commercial product, process, or service by trade name, trademark, manufacturer, or otherwise, does not necessarily constitute or imply its endorsement, recommendation, or favoring by the United States Government or the University of California. The views and opinions of authors expressed herein do not necessarily state or reflect those of the United States Government or the University of California, and shall not be used for advertising or product endorsement purposes.

This work was performed under the auspices of the U. S. Department of Energy by the University of California, Lawrence Livermore National Laboratory under Contract No. W-7405-Eng-48.

This report has been reproduced directly from the best available copy.

Available to DOE and DOE contractors from the

Office of Scientific and Technical Information

P.O. Box 62, Oak Ridge, TN 37831

Prices available from (423) 576-8401

http://apollo.osti.gov/bridge/

Available to the public from the National Technical Information Service

U.S. Department of Commerce 5285 Port Royal Rd., Springfield, VA 22161

http://www.ntis.gov/

OR

Lawrence Livermore National Laboratory Technical Information Department's Digital Library http://www.llnl.gov/tid/Library.html 


\title{
Design of Storage Systems Using Multiple Storage Technologies in Renewable Systems \\ Alan Lamont
}

Lawrence Livermore National Laboratory

\begin{abstract}
Energy systems that rely on intermittent renewable sources typically use storage devices to improve their reliability. Large scale systems can be expected to cycle the storage capacity on cycles ranging from a day to a year. It can be cost effective to use several storage technologies as a system. A very efficient technology can be used for the smaller daily cycles even if it has a high capital cost. Conversely, a technology having a low efficiency but a low capital cost can be used for the larger longer period cycles. This paper presents a method for determining the optimal capacities for a set of storage technologies. It is analogous to techniques used in electric generation capacity planning that use a load duration curve along with the capital and operating costs of various generations technologies. Here we derive a function that describes throughput as a function of capacity and use it along with the capital and operating costs (including efficiencies) of the storage technologies to derive the optimal capacities.
\end{abstract}

\section{Introduction}

Energy systems based on intermittent renewable resources will generally use storage devices to improve their reliability. Small scale systems may only have enough storage to accommodate a daily cycle of energy supply plus enough for a few days of low energy availability. Larger systems may require enough storage capacity to accommodate inter-seasonal storage.

We can conceptually divide the annual cycle of a storage system into components of storage capacity that are cycled over different periods. Some small amount of capacity might be cycled on a daily basis and thus have a high throughput compared to the capacity. Another portion of the capacity might only be cycled one time (eg over a yearly cycle) and thus may have a low throughput compared to the capacity. At the same time, storage devices have a range of operating and capital costs. In general, devices that are highly efficient will be preferred for the 
components of capacity that are cycled frequently. This will generally be true even if the capital cost of storage capacity is large, since relatively little capacity must be purchased compared tot he total throughput. At the same time devices with low capital costs will be preferred for those components of storage that are cycled occasionally. If the device is only cycled occasionally, the total costs due to throughput will tend to be small even if the efficiency is low and other operating costs are high.

This paper presents a method for decomposing the annual storage cycle into components to minimize the total operating and capital costs of the storage system. The basic approach is similar to that used for electric generation capacity planning.

\section{Motivation}

As an example, we can use a model that we developed to study an all renewable system that served electric demand and provided hydrogen as a transportation fuel (Berry et al). The system used hydrogen as a storage medium and an energy carrier. Figure 1 illustrates the model system. It was scaled to have a peak electric output of $1 \mathrm{~kW}$ and the transportation demands were scaled accordingly. In this model, all energy, including hydrogen, was measured in terms of kWh. For reference, one $\mathrm{kg}$ of hydrogen is $33.3 \mathrm{kwh}$ (lower heating value). 
Figure 1: Illustration of system using renewable electricity to meet both electric loads and transportation fuel demands. Both short term (high efficiency and higher capital costs) and long term (lower efficiency and lower capital cost) storage technologies are used.

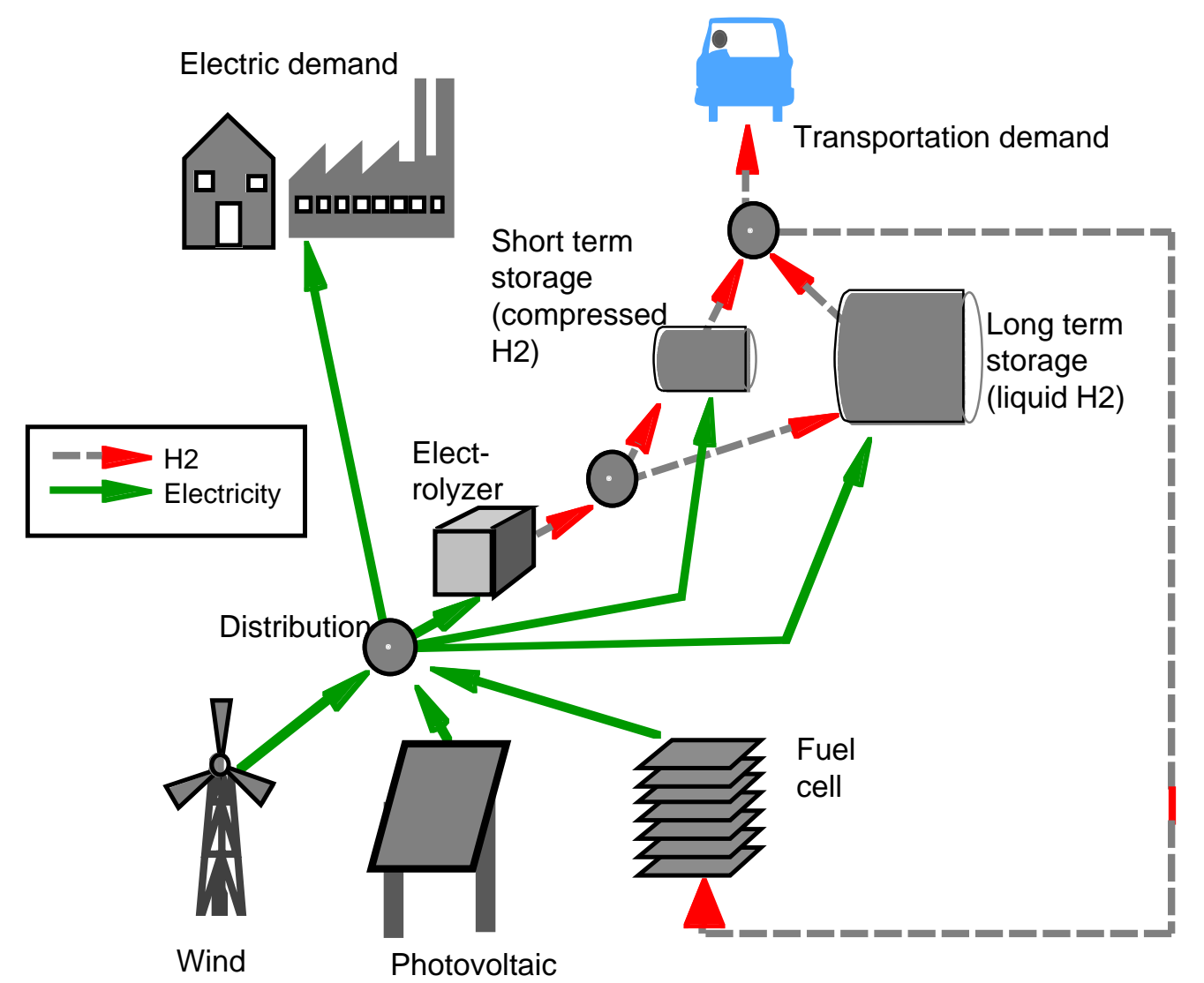

The results from this model are used here to illustrate the analysis of storage capacities. The analysis assumed operation over a full year so storage had to handle both daily and seasonal cycles. Figure 2 shows a typical annual storage profile (total amount in storage at each hour). This profile was computed assuming a system of storage devices and thus includes storage losses. 
Figure 2: Example annual storage profile for one year's operation. The first hour is midnight, January 1

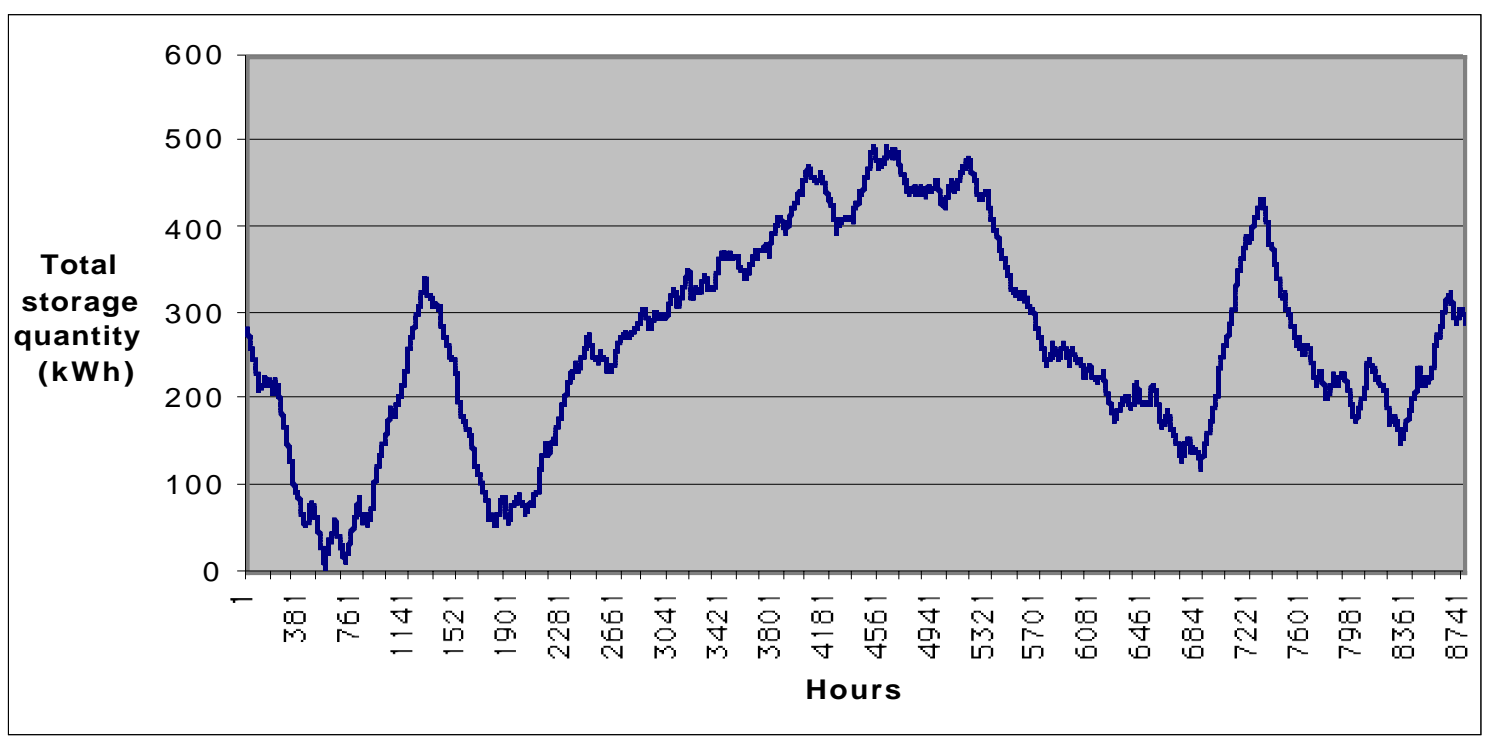

To improve the economics of the system it was assumed that compressed hydrogen would be used for short term storage due to its low operating cost (high efficiency), and liquid hydrogen would be used for long-term storage due to its low capital cost. Finding the right mix of long and short term storage was important to optimizing the overall system. Optimization by trial and error was tedious considering that a number of other variables had to be optimized simultaneously. Thus we sought a method to optimize the mix of storage technologies.

Many analyses analyze the tradeoff between generating capacity and total storage capacity to find the optimal storage capacity (see yet to come ). This is an essential step in preparing an efficient design and was part of our analysis as well. However, few if any analyses deal with the design of multiple types of storage capacity.

\section{Approach}

The approach taken here is analogous to the "load duration curve" method for electric utility capacity planning. That approach begins with an hour-by-hour annual profile of the loads that the system must meet along with the capital and operating costs of the various devices (generators) that can be used to meet them. The annual load profile is converted into the load duration curve which summarizes the essential features of the annual load profile. The method then uses the cost characteristics of the different types of generators to determine the 
optimal capacity for each type of generator. The method described here for planning storage develops a somewhat analogous summary function for the hour-by-hour storage demands and uses it to design the storage capacities based on capital and operating costs of storage devices.

\section{Basic assumptions}

First, we assume that the storage profile to be met is not significantly affected by the storage design itself. In fact, the storage profile may have some dependence on the design of the storage system. In principle, a complete analysis might require an iteration in design where a storage profile is generated based on a storage design, a new storage design is computed based on the storage profile, then a new storage profile is computed with the new selection of devices. In practice, we found the changes in the storage profile due to small changes in the storage devices were small to negligible.

The throughput of a storage device is the total amount of material (in the case of an energy carrier, such as hydrogen), or energy, that is put into the device over the analysis horizon. It is assumed that whatever is put in is eventually taken out. Here we assume that the throughput of the storage system as a whole is equal to the sum of the throughputs of the individual devices. This essentially assumes that material is not transferred from one storage device to another.

Similarly, it is assumed that the total amount of storage capacity required is equal to the sum of the capacities of the individual devices.

The operating cost of a storage device is a key concern. The operating cost might include wear and tear on pumps and compressors, labor, plus the cost of the energy expended (or lost) in storing the material. The cost of the energy expended can be measured as the cost of additional generating capacity and operation needed to provide the lost energy. Here the operating cost is measured in terms of cost per unit throughput.

The capital cost of a device is the cost of the facility used to store the material (or the energy). This would be the cost of the tanks in the case of compressed or liquid hydrogen storage. This is measured in cost per unit of storage capacity.

The capital cost defined here does not include the cost of the auxiliary equipment used to actually prepare the material (or energy) for storage. For liquid or compressed hydrogen this would be the 
compressors and chillers used to put hydrogen into the storage device. The capacities of these devices, and thus their capital costs, is primarily dependent on the rate at which energy must be put into or taken out of storage. This in turn is primarily a function of time histories of energy use and energy availability. It is only secondarily determined by the capacities of the storage systems. Thus, for a given set of technologies, the optimization of the storage system capacities is either unaffected, or only slightly affected, by these costs and can be ignored for this analysis. The cost of the auxiliary equipment can be accounted for in the broader analysis: For a given set of technologies we use the method discussed here to determine the capacity of each technology. This gives the minimum cost storage system, given that we will use that set of technologies. We can then compare the cost of one candidate set of technologies to the cost of other candidate sets to identify the best set of technologies, and the capacities of the each technology.

\section{Developing the model}

The overall objective is minimization of the total annual cost of the storage system. This is the cost of the capacity plus the cost of the throughput. The design variables are the capacities of the various devices in the system. For convenience we will assume that there are only two storage devices. The basic approach can then easily be extended to multiple devices.

Equation 1 shows the basic cost calculation as a function of capacities. Note that the throughput, V, for a device is a function of its capacity. Strictly speaking it is a function of the capacities of all the devices in the system. However, for a two device system fixing the capacity of one device fixes the capacity of the other since their sum is equal to the total system capacity, which is assumed constant.

$$
\mathrm{C}_{\mathrm{T}}=\sum_{\mathrm{i}}\left[\operatorname{Cap}_{\mathrm{i}} \bullet \mathrm{Cc}_{\mathrm{i}}+\mathrm{Cs}_{\mathrm{i}} \bullet \mathrm{V}_{\mathrm{i}}\left(\mathrm{Cap}_{\mathrm{i}}\right)\right]
$$

where

$\mathrm{C}_{\mathrm{T}}=$ total annual cost

$\mathrm{i}=$ technology type

$\mathrm{Cap}_{\mathrm{i}}=$ capacity of type $\mathrm{i}$

$\mathrm{Cc}_{\mathrm{i}}=$ annual cost per unit of capacity of $\mathrm{i}^{\text {th }}$ technology 
$\mathrm{Cs}_{\mathrm{i}}=$ cost per unit throughput for technology $\mathrm{i}$

$\mathrm{V}_{\mathrm{i}}=$ throughput for technology $\mathrm{i}$

To find an expression for the optimal capacities we differentiate with respect to the capacity of the ith technology

$$
\frac{\partial \mathrm{C}_{\mathrm{T}}}{\partial \mathrm{Cap}_{\mathrm{i}}}=\mathrm{Cc}_{\mathrm{i}}+\mathrm{Cs}_{\mathrm{i}} \frac{\mathrm{dV}_{\mathrm{i}}\left(\mathrm{Cap}_{\mathrm{i}}\right)}{\mathrm{dCap}}+\sum_{\mathrm{j} \neq \mathrm{i}}\left(\frac{\mathrm{dCap}_{\mathrm{j}}}{\mathrm{dCap}_{\mathrm{i}}} \cdot \mathrm{Cc}_{\mathrm{j}}+\frac{\mathrm{dV}_{\mathrm{j}}\left(\mathrm{Cap}_{\mathrm{i}}\right)}{\mathrm{dCap}} \cdot \mathrm{Cs}_{\mathrm{j}}\right)
$$

Equation 2

When considering two technologies at a time, we note that the total storage capacity is just the sum of the capacities for the two devices so

$$
\frac{\mathrm{dCap}_{\mathrm{j}}}{\mathrm{dCap}_{\mathrm{i}}}=-1
$$

Equation 3

Similarly, the sum of the throughput for the two devices is equal to the total throughput so the derivative of the throughput for device $\mathrm{j}$, taken with respect to the capacity of device $i$ is just the negative of the derivative for device i:

$$
\frac{\mathrm{dV}_{\mathrm{j}}\left(\operatorname{Cap}_{\mathrm{i}}\right)}{\mathrm{d} \operatorname{Cap}_{\mathrm{i}}}=-\frac{\mathrm{dV}_{\mathrm{i}}\left(\operatorname{Cap}_{\mathrm{i}}\right)}{\mathrm{d} \operatorname{Cap}_{\mathrm{i}}}
$$

Equation 4

We can substitute to obtain an expression in terms of capacity for device i:

$$
\frac{\partial C_{T}}{\partial \operatorname{Cap}_{i}}=C c_{i}+C s_{i} \frac{d V_{i}\left(\operatorname{Cap}_{i}\right)}{d \operatorname{Cap}_{i}}-C c_{j}+\frac{d V_{i}\left(\operatorname{Cap}_{i}\right)}{d \operatorname{Cap}_{i}} \cdot C s_{j}
$$

Equation 5

Setting the derivative to 0 and collecting terms we obtain: 


$$
\frac{d V_{i}\left(\mathrm{Cap}_{i}\right)}{\mathrm{dCap}}=\frac{\mathrm{Cc}_{\mathrm{j}}-\mathrm{Cc}_{\mathrm{i}}}{\mathrm{Cs}_{\mathrm{i}}-\mathrm{Cs}_{\mathrm{j}}}
$$

Equation 6

We call the term $\frac{\mathrm{Cc}_{\mathrm{j}}-\mathrm{Cc}_{\mathrm{i}}}{\mathrm{Cs}_{\mathrm{i}}-\mathrm{Cs}_{\mathrm{j}}}$ the "critical derivative" for the technology pair $i$ and $j$. Thus the optimal capacity for technology $i$ is the amount of capacity such that the derivative of throughput with respect to capacity is equal to the critical derivative.

Equation 6 has a natural interpretation: increasing capacity of device $\mathrm{i}$ by one unit increases the volume through the device by some delta. The change in capacity costs should be just offset by the change in operating costs.

\section{Construction of function V(Cap)}

The critical information needed to apply Equation 6 is the function $\mathrm{V}_{\mathrm{i}}\left(\mathrm{Cap}_{\mathrm{i}}\right)$ which gives the total throughput for a device as a function of its capacity. Since we are constructing the model for a system with two technologies, it is convenient to derive the function for the technology with the lowest operating cost. This is the technology that will be used whenever possible. Here we call the technology with the lowest operating cost the "short term" storage, and denote it with the subscript "s". The technology with the higher operating cost will be called the "long term" storage.

We construct the throughput function for the short term storage, $\mathrm{V}_{\mathrm{s}}\left(\mathrm{Cap}_{\mathrm{s}}\right)$, by postulating a set of capacities for the short-term storage. For each value of short term storage capacity, we determine the time history of filling and emptying the long-term storage device. From this we can derive the throughput for both storage devices.

There are an infinite number of trajectories for filling the long-term storage which all have the same throughput for the two storage devices. The only essential consideration is that the long-term storage device should not be cycled any more than necessary. Here we define a procedure for finding a trajectory of long-term storage levels that meets the requirements and is easy to implement in a spreadsheet. 


\section{Define the feasible band}

We begin by graphing the total amount of storage required at each period. Then we subtract off the postulated short term capacity. This gives us two curves with a band between them. Logically we know that the trajectory of long-term storage must fall inside this band: It cannot be below the band since that would imply that the amount in short term storage exceeds the postulated short-term capacity. It cannot be above this band since that would mean that the total amount in storage is greater than required. Figure 3 illustrates the total amount in storage and the feasible band. Note that we do not let the feasible band go below 0 .

Figure 3: The total storage requirement at each period and the total minus the proposed amount of short term storage. The band between these two curves is the "feasible band"

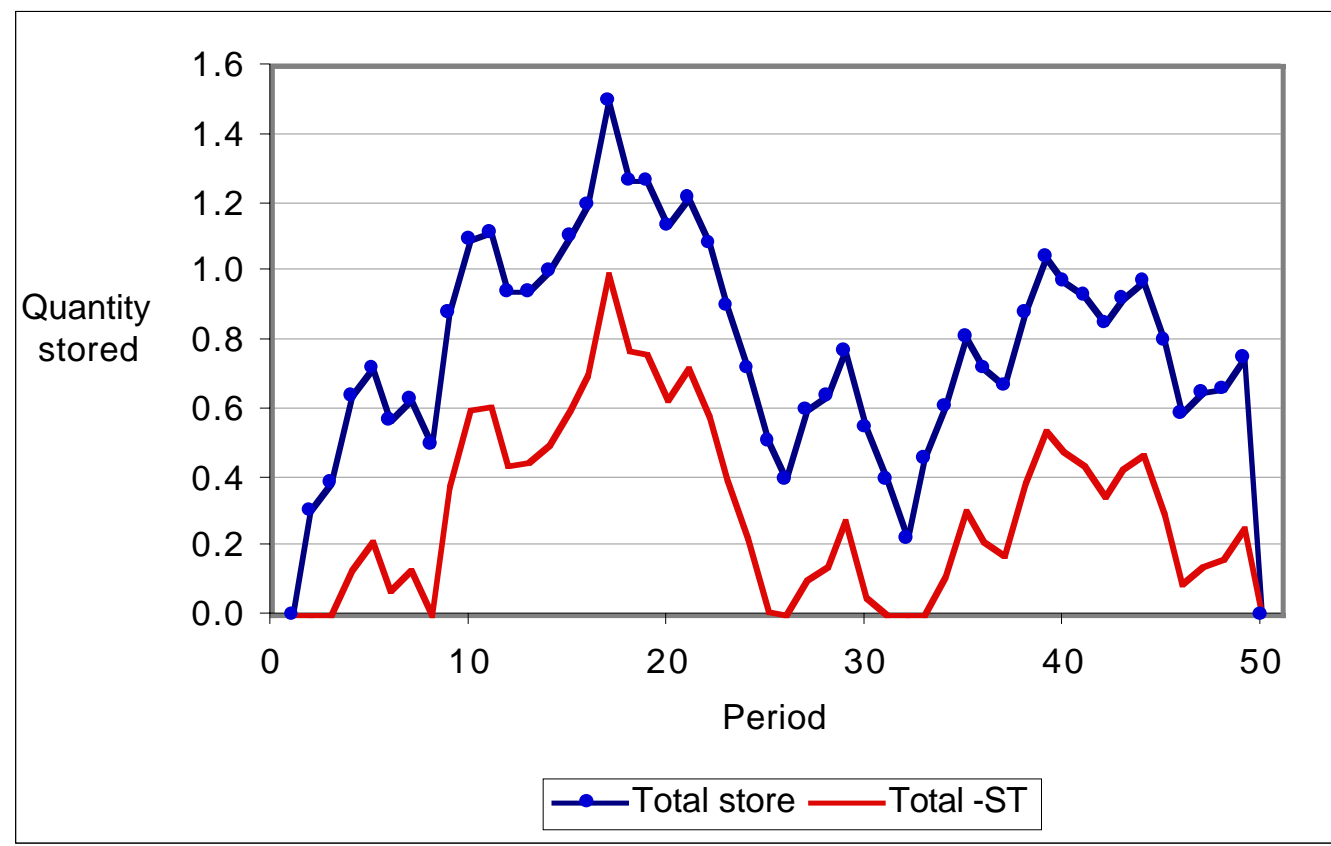

\section{Determine trajectory of filling for long-term storage}

We need to find a trajectory that does not cycle the long-term storage more than necessary. There are an infinite number of trajectories that all cycle the devices by the same amount. Here we present a rule that can be implemented in a spreadsheet to compute such a trajectory. 
To begin we need to determine whether or not to fill or empty the long-term storage at each hour of the year. Assume that the long-term storage for some period is at some level within the band. To determine whether or not we are allowed to fill or to empty long-term storage at that period, assume that long-term storage level was kept constant for the next several periods. If we project out a constant level we will eventually violate one of the bounds on the band, either the upper bound or the lower bound. If we violate the lower bound, we know that it would be inefficient to release from long-term storage since we will eventually need to fill it again. We can either leave the storage at the same level, or fill it by a small increment.

If the projection encounters an upper bound we know that it will be inefficient to fill long-term storage since we will eventually have to release whatever we added. Again, in this situation we can leave the level the same or release a small increment.

Thus, for any level of filling, at any period, we can determine whether or not it is efficient to fill or release. Note that if we are at one of the bounds, then we must fill (if it is a lower bound) or release (if it is an upper bound).

This suggests a simple rule. Basically, the level of long term storage is only changed when necessary to stay within the feasbile band. From the above discussion, this avoids any ineffiecient filling or emptying of the long-term storage. The algorithm is:

1) Start in period $i$ with a storage level $S_{i}$

2) If $U_{i+1}>S_{i}>L_{i+1}$ then $S_{i+1}=S_{i}$

3) If $U_{i+1}<S_{i}$ then $S_{i+1}=U_{i+1}$

4) If $L_{i+1}>S_{i}$ then $S_{i+1}=L_{i+1}$

Where

$\mathrm{U}_{\mathrm{i}} \quad=\quad$ upper bound in period $\mathrm{i}$,

$\mathrm{L}_{\mathrm{i}} \quad=\quad$ lower bound in period $\mathrm{i}$, and

$\mathrm{S}_{\mathrm{i}} \quad=\quad$ storage level of long-term storage in period $\mathrm{i}$

The heavy line in Figure 4 shows the results of applying the rule to this simple case. 
Figure 4: The trajectory for filling and emptying the long-term storage based on the above rule.

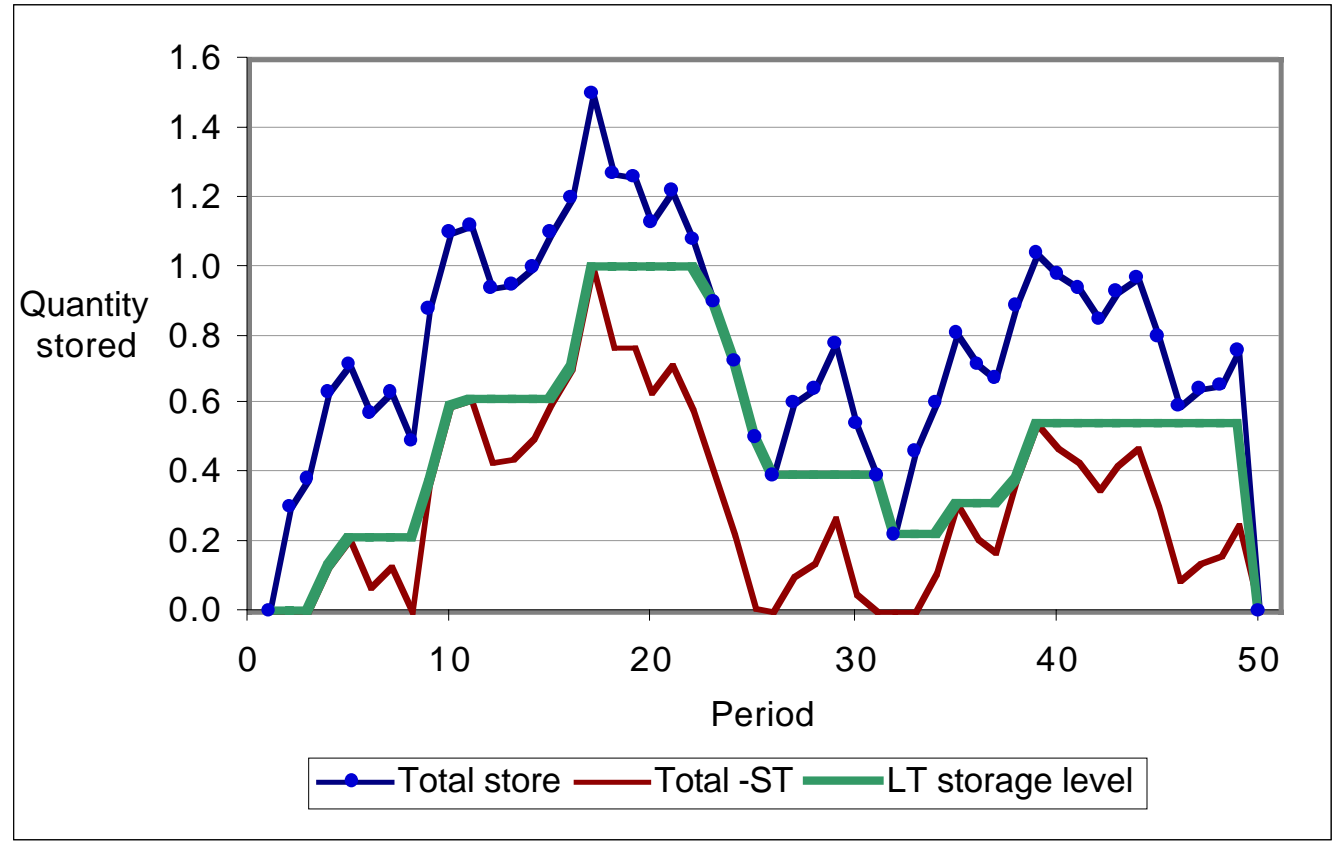

The throughput for the long term storage can be computed from its trajectory (it is the sum of all the amounts added to storage). The short-term throughput is just the total throughput minus the long-term throughput.

This establishes one point on the curve $\mathrm{V}_{\mathrm{s}}\left(\mathrm{Cap}_{\mathrm{s}}\right)$. We repeat the procedure for a series of values of short-term capacity to establish the entire curve. Figure 5 shows the curve constructed for the storage profile shown in Figure 2. The derivative of the curve can be computed numerically. This is shown in Figure 6. 
Figure 5: Derived curve of short-term storage throughput as a function of its capacity, $\mathrm{V}_{\mathrm{s}}\left(\mathrm{Cap}_{\mathrm{s}}\right)$

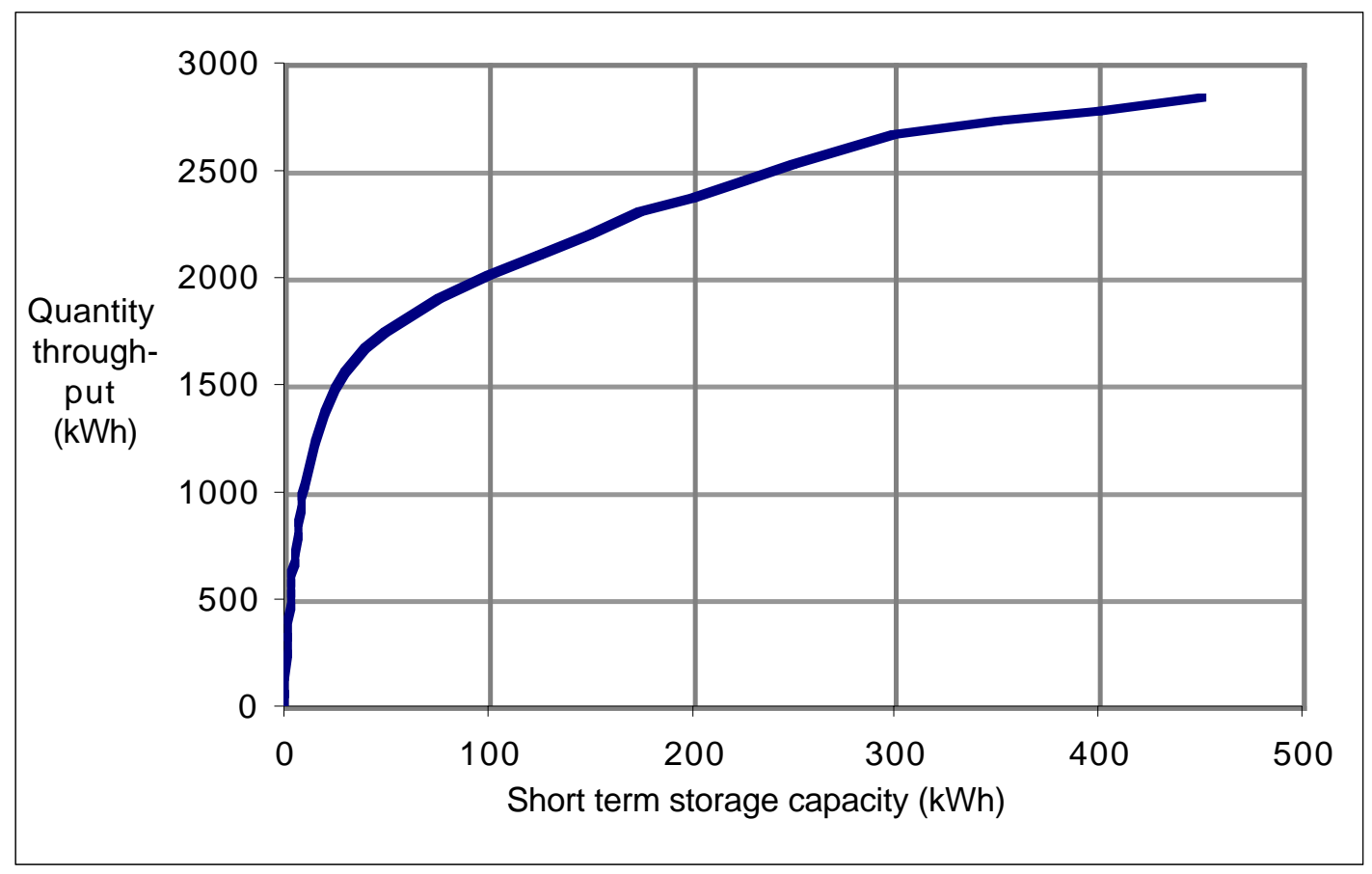


Figure 6: The derivative of throughput with respect to capacity for the short term storage

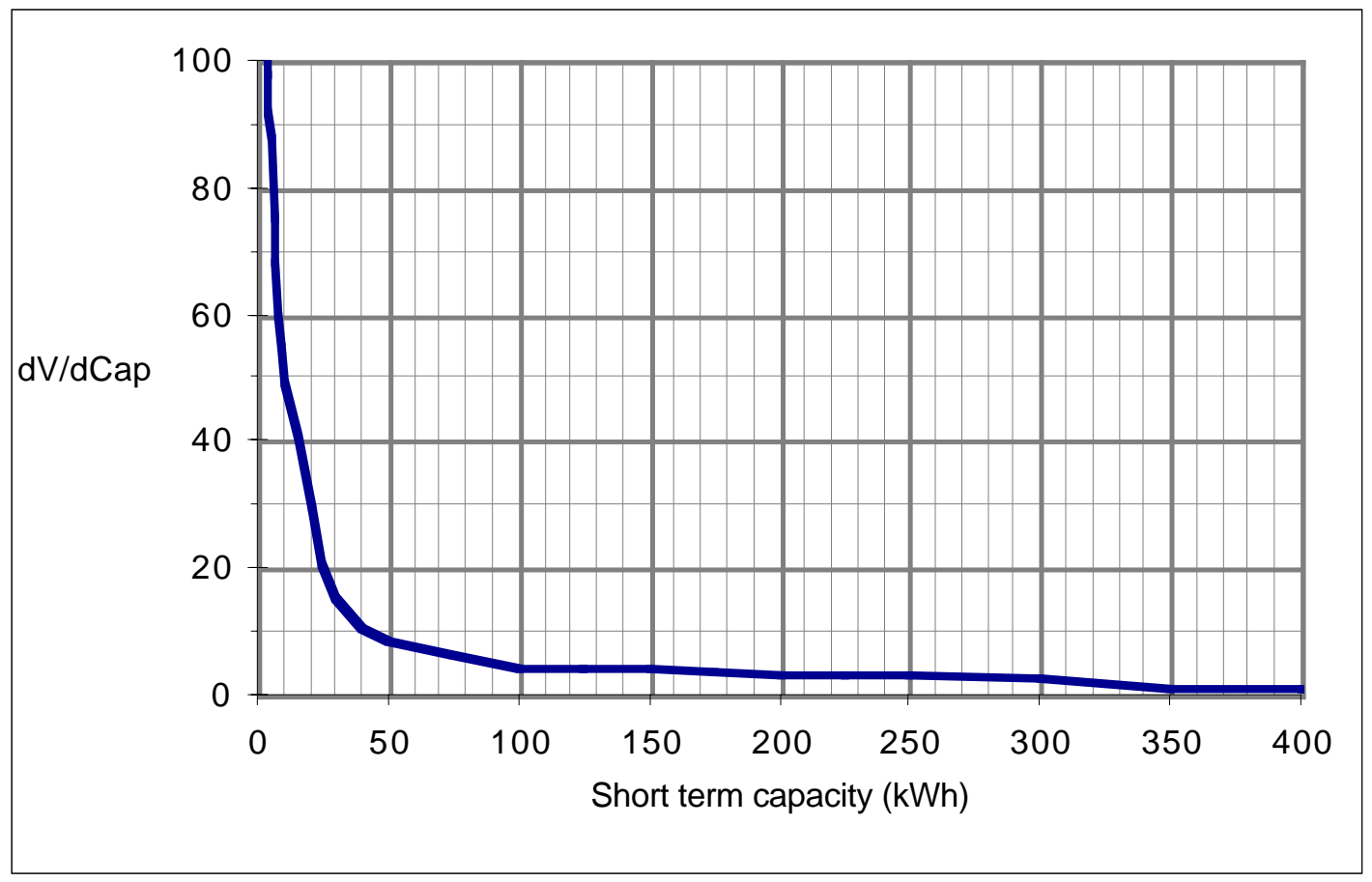

\section{Designing for more than two storage technologies}

The function $\mathrm{V}_{\mathrm{s}}\left(\mathrm{Cap}_{\mathrm{s}}\right)$ can be used to design systems with any number of technologies. The technologies are ordered by operating cost (analogous to a merit order dispatch for generation) and compared two at a time. For each comparison, the technology with the smaller operating cost is considered to be the "current short-term" storage technology. We can then compute the critical derivative and determine a capacity for the current short-term. However, the capacity determined at this point is the total capacity of the short term technologies. That is, it is the capacity of the current short term technology plus the capacities of all the technologies that have even smaller operating costs.

We can work through the technologies comparing them in order of operating cost and build up the total capacities of each technology.

\section{Example calculation of capacities}

In this example we compare three technologies: compressed hydrogen, liquid hydrogen, and chemical (eg ammonia). The compressed hydrogen is the most efficient but has the highest capital cost, while the 
chemical is the least efficient but has the lowest capital cost. In this example it is assumed that the only operating cost is electricity. The amount of electricity required per unit of hydrogen stored is reflected in the loss per unit stored, or (1-efficiency). Table 1 shows illustrative values for capital and operating costs. These calculations assume electricity price of $5 \mathrm{cents} / \mathrm{kWh}$. Note that Figure 1 indicates that the total storage capacity requirement is $496 \mathrm{kWh}$

The comparison between compressed and liquid hydrogen indicates that the critical derivative is 30.7. From Figure 6 the corresponding capacity is $20 \mathrm{kWh}$. Thus the total amount of compressed hydrogen storage should be $20 \mathrm{kWh}$.

The comparison between liquid hydrogen and chemical indicates that the critical derivative is 1.2 , so the breakpoint between them is at $350 \mathrm{kWh}$ of "short-term" storage. Recall that for this comparison, the current short-term storage is liquid hydrogen. The $350 \mathrm{kWh}$ of capacity is actually the sum of the liquid capacity plus the compressed capacity. Therefore, the compressed capacity is $24 \mathrm{kWh}$ and the liquid capacity is $(350-24)=326 \mathrm{kWh}$. Since the total required capacity is $496 \mathrm{kWh}$, the desired chemical storage is $(496-350)=146 \mathrm{kWh}$. 
Table 1: Calculation of optimal capacities for compressed hydrogen, liquid hydrogen, and chemical storage.

\begin{tabular}{|l|c|c|}
\hline \multicolumn{1}{|c|}{ Case } & $\begin{array}{c}\text { Compare } \\
\text { compressed } \\
\text { and liquid } \\
\text { hydrogen } \\
\text { storage }\end{array}$ & $\begin{array}{c}\text { Compare } \\
\text { Liquid } \\
\text { hydrogen } \\
\text { and } \\
\text { chemical }\end{array}$ \\
\hline Short term storage technology for the comparison pair & compressed & stgrage \\
\hline Long term storage technology for the comparison pair & liquid & chemical \\
\hline $\begin{array}{l}\text { Capital cost of short-term technology } \\
\text { (cents/kWh stored) }\end{array}$ & 48.00 & 2.00 \\
\hline $\begin{array}{l}\text { Capital cost of long-term technology } \\
\text { (cents/kWh stored) }\end{array}$ & 2.00 & 0.50 \\
\hline Loss, short-term (kWh lost/kWh throughput) & 0.10 & 0.40 \\
\hline $\begin{array}{l}\text { Operating cost, short-term (cents/kWh throughput) at } \\
5 \text { \$/kWh }\end{array}$ & 0.50 & 2.00 \\
\hline Loss, long-term (kWh lost/kWh throughput) & 0.40 & 0.65 \\
\hline $\begin{array}{l}\text { Operating cost, long-term (cents/kWh throughput) at } \\
5 \text { \$/kWh }\end{array}$ & 2.00 & 3.25 \\
\hline Critical Derivative & 30.70 & 1.20 \\
\hline $\begin{array}{l}\text { Optimal amount of short term storage (kWh) for the } \\
\text { comparison pair }\end{array}$ & 20 & 350 \\
\hline \hline
\end{tabular}

\section{Total cost curves}

To illustrate the effect of storage technology choices on storage system costs, we can plot the total annual system cost. This calculation includes just compressed and liquid hydrogen storage. The proper sizing of the short term storage can save about $26 \%$ of costs compared to using no short-term storage at all. 
Figure 7: Total annual cost of storage system as a function of the amount of short-term storage

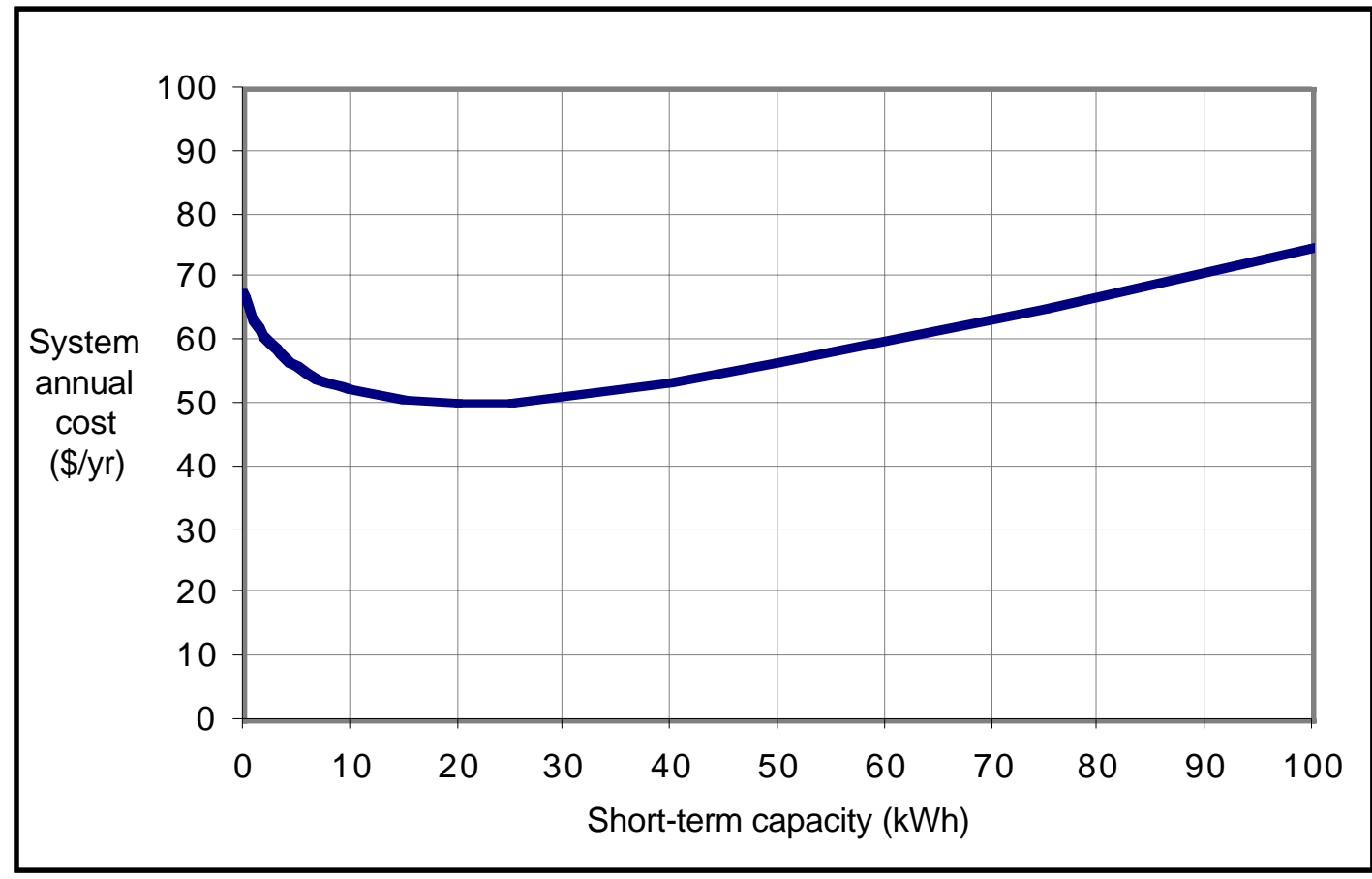

\section{Conclusions}

We have presented a method for designing storage systems based on the capital and operating costs of storage technologies and a simple transformation of the storage time history. This us to quickly find the optimal set of capacities for each technology to minimize total annual cost.

\section{References}

Yet to come

Berry et al

Original source of capacity planning method

Studies to size storage 